\title{
When Can We Rely on the Inhibitor Negativity?
}

\author{
Basak KOC ${ }^{1}$, Bulent ZULFIKAR ${ }^{1,2}$ \\ ${ }^{1}$ Istanbul University Cerrahpasa Faculty of Medicine and Oncology Institute, \\ Department of Pediatric Hematology-Oncology \\ ${ }^{2}$ The Hemophilia Society of Turkey, Istanbul, TURKEY
}

\section{Dear Editor,}

The development of inhibitors against factor VIII or IX is the most serious complication in hemophilia, occurring in approximately $30 \%$ and $5 \%$ of hemophilia A and B patients, respectively. Inhibitor development is a complex and multifactorial process influenced by a number of factors including the type of mutations, family history, intensive replacement treatment, disease severity and age at first exposure. ${ }^{1}$

The best treatment strategy for inhibitor eradication is immune tolerance induction (ITI) and bleeding episodes in these patients can be treated with bypassing agents. When inhibitors are negative, the results should be confirmed by a recovery test and the halflife of FVIII. ${ }^{2}$

A retrospective analysis of patients who had developed inhibitors and then had inhibitor negativity between 1999 and 2014 was carried out. Recovery tests were performed in 11 patients. At first FVIII and inhibitor levels were assessed and FVIII was given at a dose of $50 \mathrm{IU} / \mathrm{kg}$. Then, both FVIII and inhibitor as a Bethesda unit (BU) were measured again at 30-60 minutes and 4-6 hours. By definition, complete success level was $>66 \%$ at 30-60 minutes for recovery and $>66 \%$ at 4-6 hours for the half-life of FVIII. Patients with values below these thresholds were considered as partial responders and the remaining were classified as non-responders.
Immune tolerance induction was performed in five patients. In one of the two children inhibitor negativity was achieved at 4.5 years with successful recovery and half-life test (patient 1), and in the other child, despite negativity at around 1 year, recovery test showed only partial response $(39.6 \%)$ and ITI is currently ongoing (patient 2). Another patient (patient 3) who received several ITI treatments followed by rFVIIa, tested negative for inhibitor after 14 years. In two adult (patients 4 and 5) who had their inhibitor levels elevated after six months, ITI was terminated. Subsequently they were treated with bypassing agents, and when inhibitors tested negative under this treatment, a recovery test was performed. Initially recovery was successful and halflife of FVIII was adequate in patient 4 . But clinically he had heavy bleeding episodes and recovery test was done after 1 month and inhibitor tested positive. The results of patients shown in Table 1.

The other six patients were treated with bypassing agents only; when inhibitors tested negative, a recovery test was performed and repeated at regular intervals. In all patients, despite inhibitor negativity, the half-life of plasma FVIII was not deemed adequate. Only one patient had a partial response (recovery $49.7 \%$ and half-life $35.2 \%$ ). 
International Journal of Hematology and Oncology

\begin{tabular}{|c|c|c|c|c|c|c|c|c|c|}
\hline \multirow[t]{2}{*}{ Patient \# } & \multirow[t]{2}{*}{ Recovery \# } & \multicolumn{2}{|c|}{ 0. minute } & \multicolumn{2}{|c|}{ 30-60.minutes } & \multicolumn{2}{|c|}{ 4-6. hours } & \multirow[t]{2}{*}{ Treatment } & \multirow[t]{2}{*}{ Result } \\
\hline & & Inh (BU) & FVIII (\%) & Inh (BU) & FVIII (\%) & Inh (BU) & FVIII (\%) & & \\
\hline \multirow[t]{3}{*}{$\# 1$} & 1 & $(-)$ & $<1$ & $(-)$ & 55 & $(-)$ & 42 & ITI & PR \\
\hline & 2 & $(-)$ & $<1$ & $(-)$ & 99,6 & $(-)$ & 75.5 & $\mathrm{ITI}$ & $\mathrm{CR}$ \\
\hline & 3 & $(-)$ & & $(-)$ & 66 & $(-)$ & 55.2 & ITI & $\mathrm{CR}$ \\
\hline \multirow[t]{5}{*}{ \#2 } & 1 & $(-)$ & 0.2 & $(-)$ & 19.4 & $(-)$ & 2.2 & ITI+aPCC & $N R$ \\
\hline & 2 & $(-)$ & 0.3 & $(-)$ & 39.4 & $(-)$ & 25.8 & $\mid \mathrm{TI}+\mathrm{aPCC}$ & PR \\
\hline & 3 & $(-)$ & 0.3 & $(-)$ & 40 & $(-)$ & 24.5 & $\mid \mathrm{TI}+\mathrm{aPCC}$ & PR \\
\hline & 4 & $(-)$ & 0.3 & $(-)$ & 41.4 & $(-)$ & 36.6 & $\mid \mathrm{TI}+\mathrm{aPCC}$ & PR \\
\hline & 5 & $(-)$ & 0.3 & $(-)$ & 28 & $(-)$ & 19.7 & ITI & PR \\
\hline \multirow[t]{2}{*}{ \#3 } & 1 & $(-)$ & 0.4 & $(-)$ & 58.7 & $(-)$ & 49.8 & rFVIla & PR \\
\hline & 2 & $(-)$ & 0.7 & $(-)$ & 36.1 & $(-)$ & 44 & rFVlla & PR \\
\hline \multirow[t]{2}{*}{$\# 4$} & 1 & $(-)$ & 19.9 & $(-)$ & 85.4 & $(-)$ & 51 & rFVlla & $\mathrm{CR}$ \\
\hline & 2 & 37.5 & $<1.1$ & 7,5 & $<2$ & 37.5 & 2.3 & rFVIla & NR \\
\hline \multirow[t]{2}{*}{ \#5 } & 1 & 2.64 & $<0.2$ & 2.56 & 19.7 & 1.72 & 12.7 & rFVIla/aPCC & NR \\
\hline & 2 & 42.5 & 0.5 & 50 & 0.8 & 62.5 & 0.5 & rFVIIa/aPCC & NR \\
\hline
\end{tabular}

Management of hemophilia with inhibitors presents certain challenges. Although patients can be treated with bypassing agents on-demand or prophylactically, the main purpose is to achieve inhibitor eradication byITI. ${ }^{3-6}$ and ITI can be performed with a high (200 IU/kg/day) or low dose (50 IU/ kgx3/week) FVIII regimen. ${ }^{2}$ Five of our patients were treated with a low dose ITI regimen. Immune tolerance induction failed in 3 subjects, while it was successful in the other 2. When ITI was terminated, 1 patient (patient 4) was followed up under PCC prophylaxis and another 2 (patients 3 and 5) were treated with bypassing agents on-demand. The other 6 patients were treated on-demand. Despite being a part of treatment monitoring, we found that inhibitor negativity was not reliable. In other words, inhibitor negativity does not automatically imply that FVIII concentrate can be administered in an attempt to achieve an adequate plasma level. Similarly, inhibitor negativity in patients who receive bypassing agents, plasma factor level is not a good indicator during follow-up.
In conclusion, eradication of inhibitors and the treatment of hemophilia with inhibitors are still associated with therapeutic challenges. When inhibitors are negative, a quick switch in the treatment modality should be avoided. Inhibitor negativity must be confirmed by recovery and half-life testing of FVIII.

\section{REFERENCES}

1. Collins PW, Chalmers E, Hart DP, et al. UK Haemophilia Centre Doctors. Diagnosis and treatment of factor VIII and IX inhibitors in congenital haemophilia: (4th edition). UK HaemophiliaCentre Doctors Organization. Br J Haematol 160: 153-170, 2013.

2. Hay RMC, DiMichele DM. The principles results of the International Immune Tolerance Study: a randomized dose comparison. Blood 119: 1335-1344, 2012.

3. Zulfikar B, Aydogan G, Salcioglu Z, et al. for The Feiba Investigators Team. Efficacy of FEIBA for acute bleeding and surgical haemostasis in haemophilia A patients with inhibitors: a multicentre registry in Turkey. Haemophilia 18: 383-391, 2012. 
4. Srivastava A, Brewer AK, Mauser-Bunschoten EP, et al. Treatment guidelines working group on behalf of the the World Federation of Hemophilia. Guidelines for the management of hemophilia. Haemophilia 19: 1-47, 2013.

5. Gingeri A, Leissinger C, Cortesi PA. Health-related quality of life in patients with haemophilia and inhibitors on prophylaxis with anti-inhibitor complex concentrate: results from the ProFEIBA study. Haemophilia 19: 736-743, 2013.

6. Konkle BA, Ebbesen LS, Erhardtsen E, et al. Randomized, prospective clinical trial of recombinant factor Vlla for secondary prophylaxis in hemophilia patients with inhibitors. J Thromb Haemost 5: 1904-1913, 2007.

\section{Correspondence}

Dr. Basak KOÇ

Istanbul Üniversitesi

Çapa Tip Fakültesi

Pediatrik Hematoloji-Onkoloji Bölümü

Çapa Kampüsü

34093 Çapa, ISTANBUL / TURKEY

Tel: (+90-505) 4037491

e-mail: s_basakkoc@hotmail.com 